\title{
Extended expansion linkage engine: a concept to increase the efficiency
}

\author{
Ortwin Dumböck ${ }^{1}\left[\right.$ Eberhard Schutting ${ }^{1} \cdot$ Helmut Eichlseder $^{1}$
}

Received: 22 January 2018 / Accepted: 25 April 2018 / Published online: 18 May 2018

(c) The Author(s) 2018

\begin{abstract}
In a broad-based survey, the reciprocating piston engine with extended expansion stroke was found to have the highest efficiency potential for passenger car propulsion. To confirm the predicted efficiency, three different prototype engines were built and measured on testbed. Measurements were complemented with thermodynamic simulations. Investigations focused on naturally aspirated and supercharged SI engines. It could be shown that a naturally aspirated SI engine with an expansion ratio $\gamma$ of 2 gains an efficiency improvement of 7 percentage points compared to a conventional crank train engine. It was also found that the extended expansion has no inherent effect to combustion, emission formation and wall heat transfer. Major effort was made to assess the Miller cycle as a thermodynamic alternative to the crank train with extended expansion. Measurements and simulations revealed that Miller suffers in a way from higher wall heat and gas exchange losses cutting a substantial share of the efficiency potential of an equivalent crank train solution.
\end{abstract}

Keywords Extended expansion · Atkinson cycle $\cdot$ Miller cycle

\begin{tabular}{llll}
\multicolumn{2}{l}{ Abbreviations } & $\Delta \eta_{\mathrm{RC}}$ & Real combustion loss \\
atm & Atmospheric & $\Delta \eta_{\mathrm{WH}}$ & Wall heat loss \\
AFR & Air to fuel ratio & $\mathrm{HE}$ & Heat exchanger \\
$\mathrm{BDC}$ & Bottom dead centre & $\varphi$ & Angle \\
$\mathrm{BP}$ & Boost pressure & $\lambda$ & Stoichiometric air to fuel ratio \\
$\mathrm{CA}$ & Crank angle & $n$ & Engine speed \\
$\mathrm{c}$ & Compression & $\mathrm{NA}$ & Naturally aspirated \\
$\mathrm{COMP}$ & Compressor & $p$ & Pressure \\
$\gamma$ & Volume ratio & $Q$ & Heat \\
$\mathrm{Ex}$ & Expansion & & Stroke \\
$\mathrm{EE}$ & Extended expansion & $\mathrm{SC}$ & Supercharger \\
$\mathrm{EGBP}$ & Exhaust gas back pressure & $\mathrm{SI}$ & Spark ignited \\
$\varepsilon_{\mathrm{c}}$ & Compression ratio & $\mathrm{Tb}$ & Turbine \\
$\varepsilon_{\mathrm{Ex}}$ & Expansion ratio & $\mathrm{TC}$ & Turbocharger \\
$\mathrm{FE}$ & Fuel energy & TDC & Top dead centre \\
$\eta$ & Efficiency & $v$ & Specific volume \\
$\Delta \eta_{\mathrm{GE}}$ & Gas exchange loss & $V_{\mathrm{c}}$ & Compression volume \\
$\Delta \eta_{\mathrm{IC}}$ & Imperfect combustion loss & WOT & Wide open throttle \\
& & $1 \mathrm{D}-\mathrm{CFD}$ & One-dimensional computational fluid dynamics
\end{tabular}

Ortwin Dumböck

ortwin.d@gmx.at

Eberhard Schutting

schutting@ivt.tugraz.at

Institute of Internal Combustion Engines

and Thermodynamics, Graz University of Technology,

Styria, Austria

\section{Introduction and concept decision}

Conventional combustion engines for passenger car propulsion are already highly developed, hence it is no longer possible to reach significant efficiency improvement with 
evolutionary development. Initial objective of this thesis is to find a revolutionary new concept for a propulsion engine. A literature research and a first assessment of concepts were undertaken to identify possible solutions without any restrictions in the first instance.

Thermal engines can be divided into machines with continuous process (e.g. gas turbine) and discontinuous process (e.g. Otto process). Thermal engines can further be divided into machines with external combustion (e.g. Stirling engine) and with internal combustion (Otto process). Some simple considerations allow for a first elimination of engine concepts.

With external combustion processes it would be necessary to conduct the whole thermal energy through the wall of a heat exchanger whatsoever. Consequently, the peak process temperature and thus the thermal efficiency of the machine are limited by the temperature resistance of the used material. Right now there exists no material that can withstand temperatures that were necessary for sufficient process efficiency. Processes with external combustion were dropped for this reason.

In the case of continuous combustion, the combustion temperature would be also limited by the thermal stability of the combustion chamber gas outlet device. Processes with continuous combustion were also dropped. Thus, it is clear that a high efficiency thermal process for vehicle propulsion is discontinuous with an internal combustion (Otto process). The discontinuous operation enables high process temperatures without exaggerated temperature stress for the engine parts. Admittedly, it was somehow unexpected to end up with a rather conventional process.

The first step to refine this first selection is to identify the process changes which increase the efficiency, compared to a conventional process. Extended expansion, waste heat recirculation and advantages from cooled compression (higher compression ratio or higher potential of heat recirculation) are fundamental concepts to reduce the fuel consumption of the process.

Figure 1 shows the most relevant process adaption in the $p V$ diagram. Starting from the process of the conventional internal combustion engine, which is shown as broken line 1-2-3-4-5, an extended expansion is achieved if the volume at the end of expansion exceeds the intake volume. It is also possible to increase the efficiency using recirculated waste heat $Q_{\mathrm{HE}}$ to substitute fuel energy. The third shown measure is cooled compression in combination with waste heat recirculation. Cooled compression $1-2_{\text {cool }}$ decreases the necessary work for the compression. However, without heat recirculation, more fuel energy would be used to reach the same point 4 at the end of combustion and the efficiency would not increase. With waste heat recirculation the combustion starts at 3 instead of 2 . Thus, more work can be gained with less exerted fuel

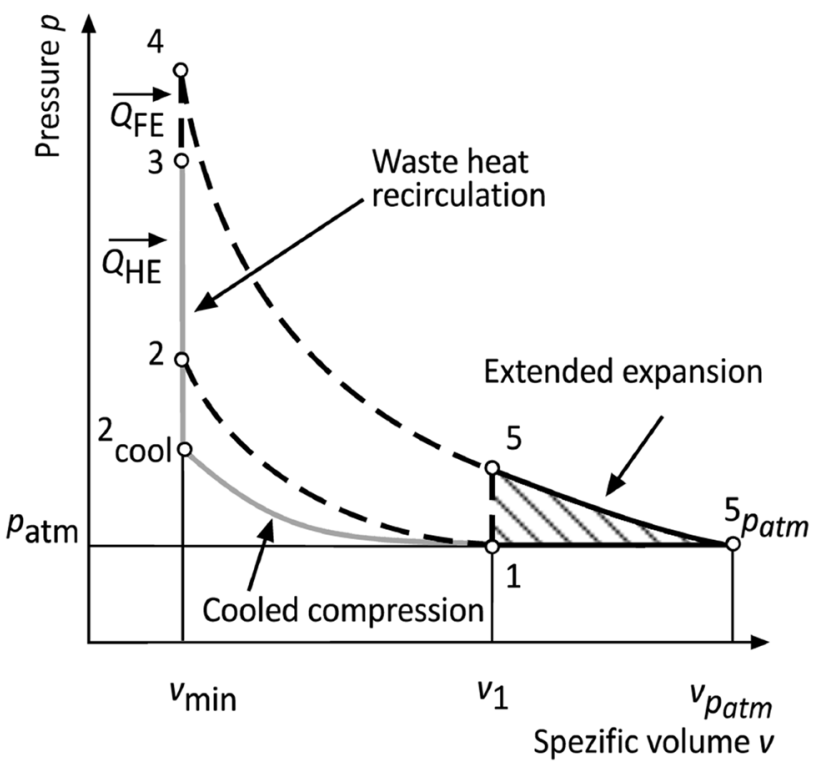

Fig. 1 Measures to increase the efficiency, shown in $p V$ chart

energy. If the compression ratio is limited by knocking, it is possible to gain additional efficiency by reducing the probability of knocking with cooled compression in combination with a high compression ratio.

New engine concepts are required to realise above described processes. For passenger car scale, reciprocating piston engines offer the best way to reach a high efficiency. Other concepts [1-4] drop out due to various disadvantages. These are either friction, combustion, wall heat losses or other-or all of them. Some of the concepts were excluded based on simple considerations, others on the basis of thermodynamic simulations.

After exclusion of obviously inappropriate machines two concepts remained for a detailed simulation analysis. These are the Atkinson Crank Train [5] and the Split Cycle Engine. The Atkinson Crank Train provides an extended expansion in one working chamber, while the Split Cycle Engine comprises two connected working chambers. The Split Cycle offers, additionally to extended expansion, the possibility of cooled compression and waste heat recirculation. Figure 2 shows an overview of the simulation results. With the results it has to be discriminated between knock-limited processes (e.g. gasoline Otto process) and not knock-limited processes (e.g. Diesel process). With 1D-thermodynamic simulations, following findings contribute to the ongoing selection process:

- Waste heat recirculation is not reasonable for processes limited by knocking (e.g. gasoline).

- Waste heat recirculation does not provide any advantage when all losses of the real process are considered (heat loss, flow resistance, valve opening). 


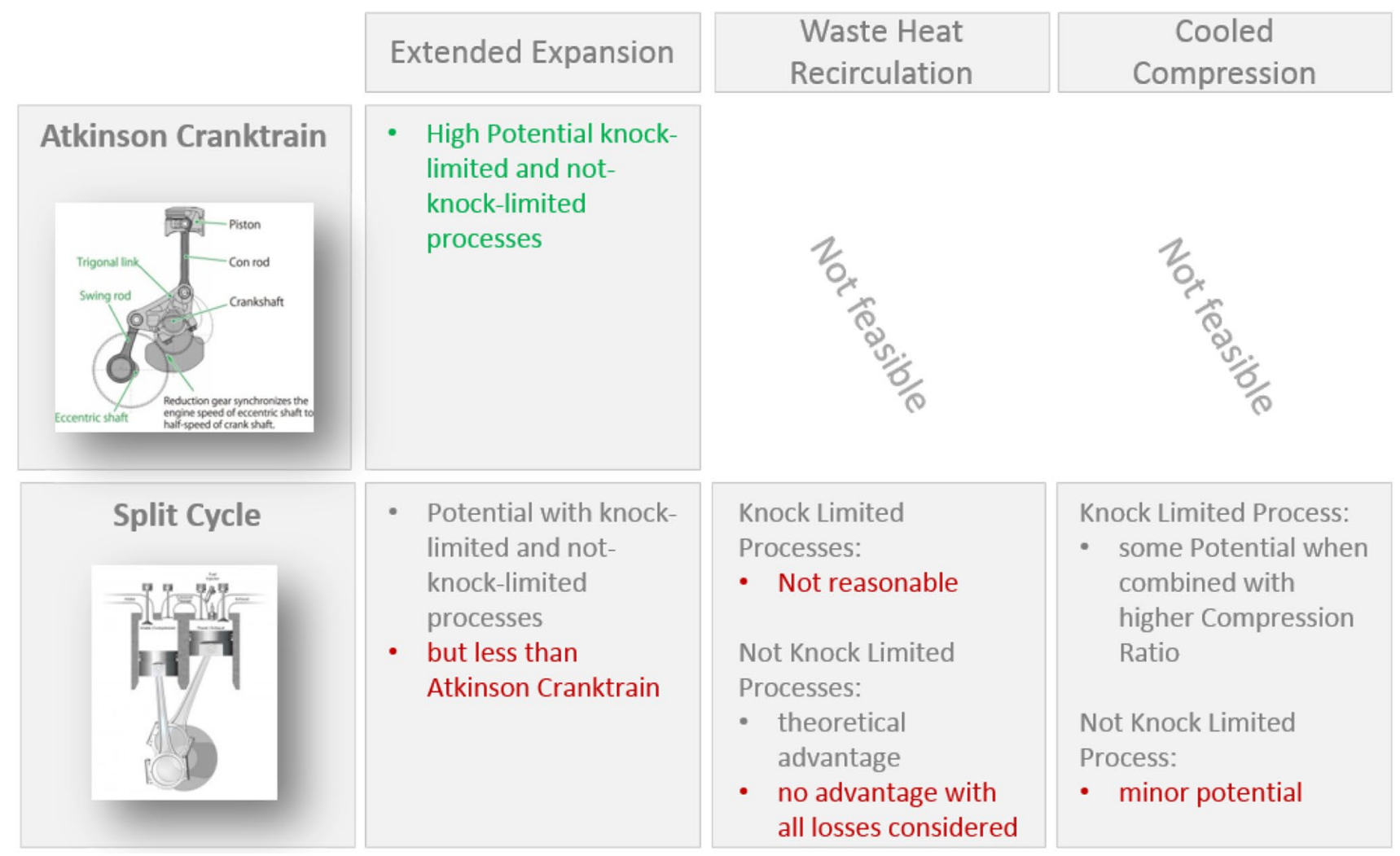

Fig. 2 Overview concept decision (pictures: Honda, Scuderi)

- Cooled compression gives some advantage when combined with higher compression ratio with knock limited processes.

- Cooled compression gives only minor advantage on processes, not limited by knocking.

After this short overview, it is clear, that the concept with extended expansion gains the highest efficiency under real conditions. In this phase of the project, the initially unrestricted investigations were focused on the stoichiometric gasoline combustion. Thus, all discussions and results are related to an Atkinson cycle engine with stoichiometric gasoline combustion henceforth.

This process is discussed in more detail in the following chapters. After some theory in Sect. 2, the mechanical realisation and the used test carriers are described in Sect. 3. Section 4 summarizes the measurement results. 1D-CFD-post processing of the measurements revealed additional insight—-see Sect. 5.

\section{Extended expansion theory}

The theoretical considerations base upon the idealized standard air fuel cycle. Figure 3 shows this idealized process with extended expansion. After the compression 1-2 and the combustion 2-3, an isentropic expansion 3-4 follows. The expansion does not end, unlike the conventional Otto process, at the intake volume $V_{\text {inlet }}$. The expansion continues until the volume $V_{\mathrm{Ex}}$ is reached. Because of this, most of the combustion pressure can be used and the shaded area of extra work is gained. In the case of the conventional engine, useful energy escapes through the exhaust system. The process with extended expansion has a short intake stroke and a long expansion stroke. Thus, an extra parameter in addition to the parameters of the conventional process is necessary to characterise the process with extended expansion. Here $\gamma$, the ratio of the volume after the expansion $V_{\mathrm{Ex}}$ and the volume before compression 


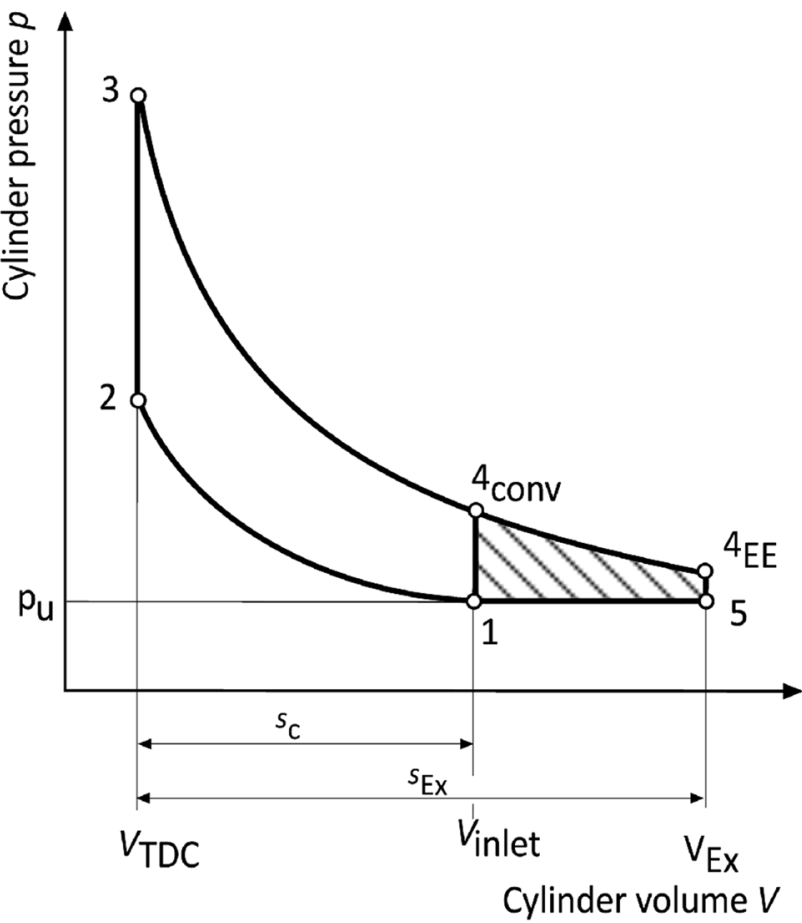

Fig. 3 Process with extended expansion in $p V$ chart

Table 1 Efficiency of the standard air fuel cycle

\begin{tabular}{llllll}
\hline$\varepsilon_{\mathrm{c}}$ & $\eta_{\gamma=1}$ & $\eta_{\gamma=1.56}$ & $\eta_{\gamma=2}$ & $\eta_{\gamma=\gamma_{p_{\text {atm }}}}$ & $\gamma_{p_{\text {atm }}}$ \\
\hline 10 & 47.3 & 53.5 & 56.1 & 60.1 & 4.43 \\
11 & 48.7 & 54.7 & 57.3 & 61.0 & 4.36 \\
12 & 49.9 & 55.8 & 58.3 & 61.8 & 4.30 \\
16 & 53.8 & 59.2 & 61.4 & 64.3 & 4.10 \\
18 & 55.3 & 60.5 & 62.7 & 65.3 & 4.03 \\
\hline
\end{tabular}

$V_{\text {inlet }}$, is used. It is also equal to the ratio of expansion ratio and compression ratio

$\gamma=\frac{V_{\mathrm{EX}}}{V_{\text {inlet }}}=\frac{\varepsilon_{\mathrm{Ex}}}{\varepsilon_{\mathrm{c}}}$.

Table 1 shows the efficiency of the stoichiometric standard air fuel cycle. It depends on the compression ratio $\varepsilon_{\mathrm{c}}$ and on the volume ratio $\gamma$. The shown volume ratios 1 , 1.56 and 2 were also realised at the test bench. Even higher volume ratios are not reasonable with mechanical crank trains. To reach an expansion to atmospheric, the necessary volume ratio $\gamma_{p_{\text {atm }}}$ would be higher than four.

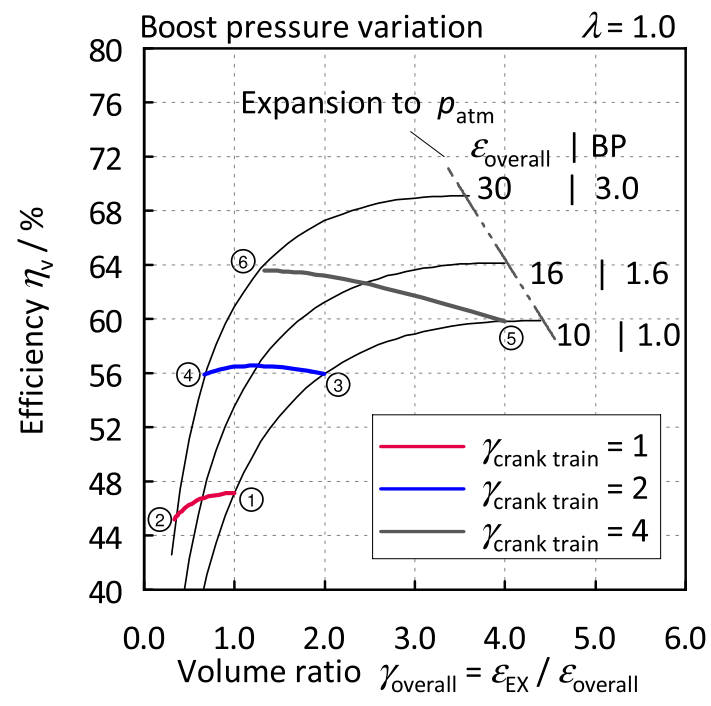

Fig. 4 Influence of the supercharger on the engine with extended expansion (standard air fuel cycle)

The process with extended expansion is similar to the conventional process, but the influence of some parameters such as air to fuel ratio or boost pressure is not the same. An important point is the effect of different supercharging systems on the process with extended expansion.

A mechanically driven supercharger can be taken as a part of the overall compression. The overall compression ratio $\varepsilon_{\text {overall }}$ is the product of supercharger-compression and cylinder-compression. The overall volume ratio $\gamma_{\text {overall }}$ is the ratio of the overall compression ratio $\varepsilon_{\text {overall }}$ and the expansion ratio $\varepsilon_{\mathrm{Ex}}$ of the crank train.

The overall compression ratio $\varepsilon_{\text {overall }}$ increases with supercharging. Hence, the overall volume ratio $\gamma_{\text {overall }}$ decreases, because the engine expansion ratio remains unaffected by the supercharging. In Fig. 4, this correlation is depicted. The plot shows the theoretical efficiency $\eta_{\mathrm{v}}$ versus $\gamma_{\text {overall }}$. There is an array of thin black curves which represents the efficiency as function of the volume ratio $\gamma$ for fixed boost pressures (BP). The red curve shows the efficiency of a conventional engine. Starting from naturally aspirated operation (1), the efficiency drops with increasing supercharging pressure (2). The influence of the decreasing overall volume ratio $\gamma_{\text {overall }}$ near the value 1 is higher than the influence of the increasing compression ratio $\varepsilon_{\text {overall }}$. This meets the expectation of mechanical supercharging.

In the case of a crank train with a volume ratio of two (blue line), the efficiency increases slightly (3) $\rightarrow$ (4). So it is possible to increase the power density and the efficiency by supercharging. A crank train with a volume ratio of four (black line) shows a strong increase of the efficiency by super charging (5) $\rightarrow$ (6). 


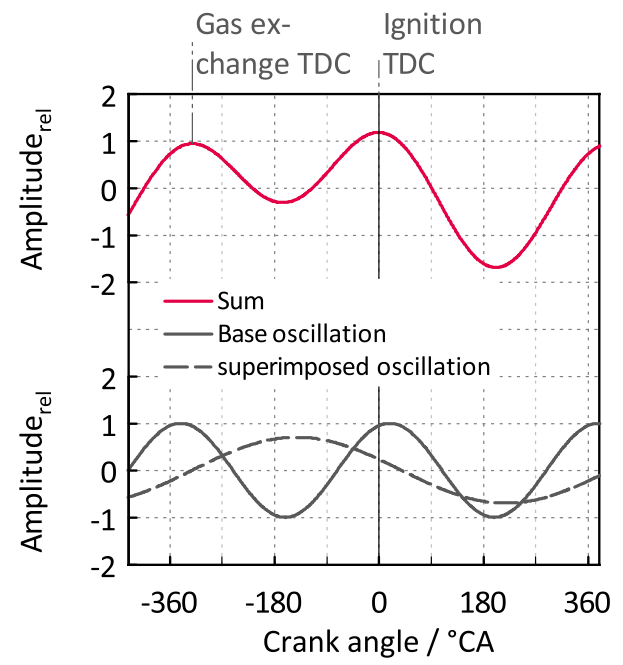

Fig. 5 Principle of the extended expansion

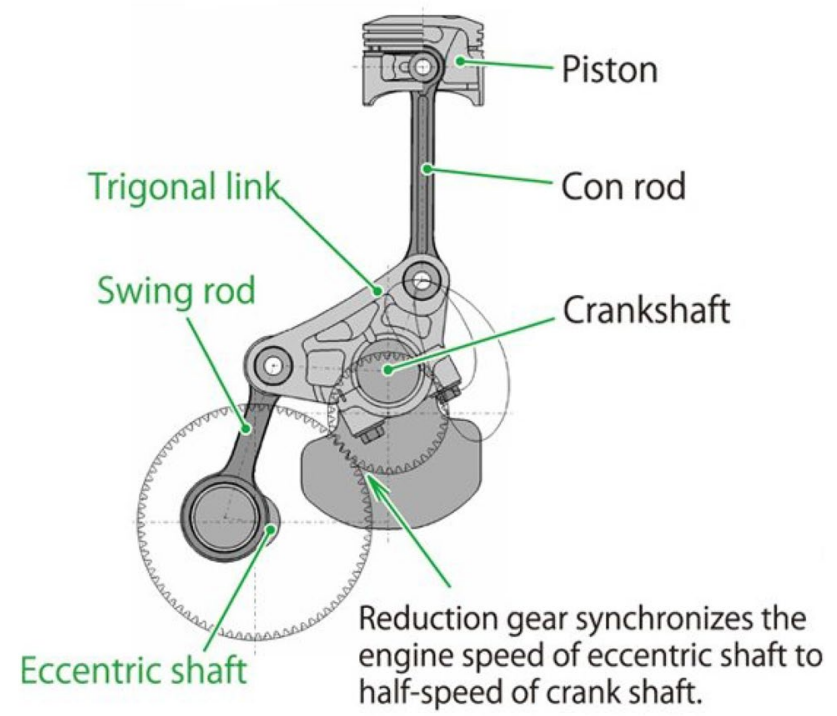

Fig. 6 Honda exlinkage (source: Honda)

\section{Realisation of the process with extended expansion}

The realisation of the extended expansion is possible by a special crank train (Atkinson cycle) or by Miller valve timing with a conventional engine. There exist other concepts with extra expansion machines but these are not investigated here in detail. Their potential is limited [6].

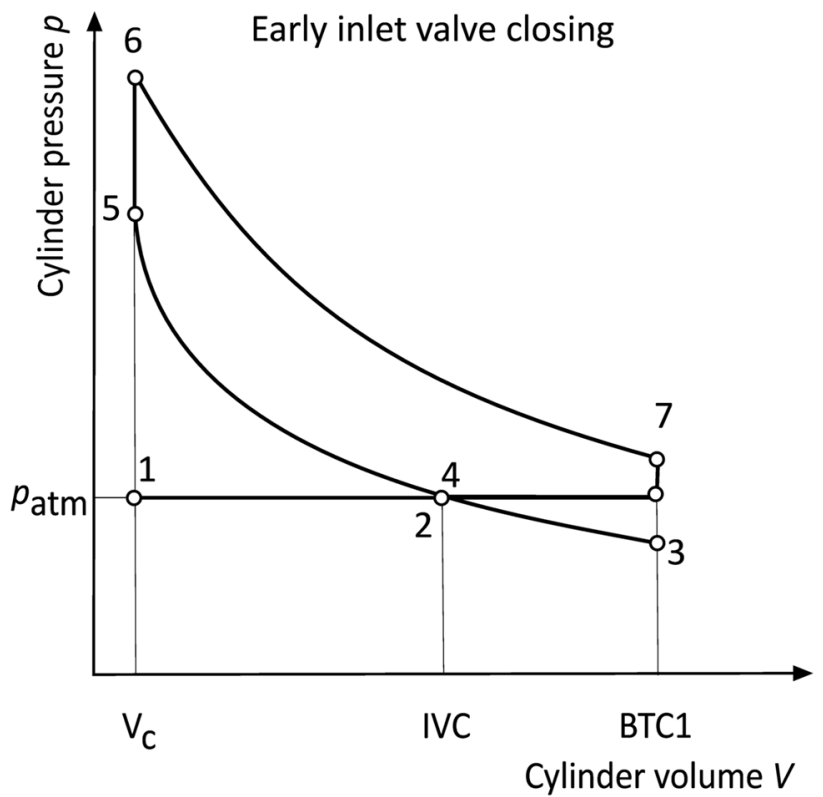

Fig. 7 Miller timing

\subsection{Crank train realisation}

Figure 5 shows the principle of crank trains for extended expansion. The idea is to superimpose the oscillation of the crank train and a second oscillation with half the frequency. The result of this summation is the shown oscillation (red line). Every second outward stroke is longer. For the crank train realisation of this principle, some solutions are known. One possibility is the Honda linkage [7] which is shown in Fig. 6 . The test carrier here uses the same design principle as Honda.

\subsection{Miller realisation}

Another possibility for extended expansion is a conventional crank train with Miller timing [8] which is shown in Fig. 7. One variant of Miller timing is an early inlet valve closing. The inlet valve closes before bottom dead centre. Because of this, the air inside the cylinder expands to low temperature and pressure. After the recompression to point 4, the same condition as at point 2 is reached. The work of the expansion compensates the used work for the compression. Because of this, the effective compression begins at 4 . So, the expansion stroke is longer than the effective compression stroke. ${ }^{1}$

\footnotetext{
${ }_{1}$ Alternatively, the intake valve can be closed late. The theoretical process is identical.
} 


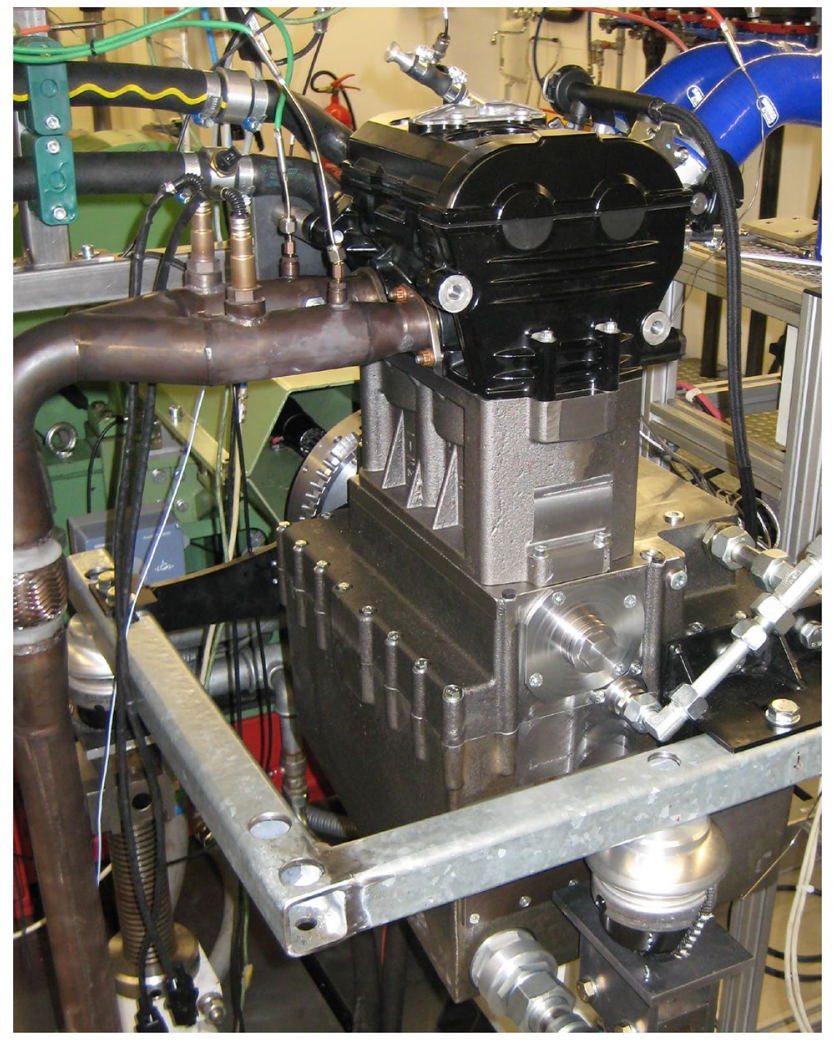

Fig. 8 Test carrier $(\gamma=2)$ with series cylinder head and prototype crank train

Table 2 Dimension of the experimental engines

\begin{tabular}{llllll}
\hline Volume ratio $\gamma$ & 1 & 1.56 & 2 & Miller & \\
\hline$\varepsilon_{\mathrm{c}}$ & 12 & 12 & 12 & 18 & - \\
Bore & 82 & 82 & 82 & 82 & $\mathrm{~mm}$ \\
Stroke $s_{\mathrm{c}}$ & 75.6 & 75.6 & 60.8 & 75.6 & $\mathrm{~mm}$ \\
Stroke $s_{\text {Ex }}$ & 75.6 & 122.5 & 126.9 & 75.6 & $\mathrm{~mm}$ \\
Stroke ratio & 1 & 1.62 & 2.09 & 1.00 & - \\
\hline
\end{tabular}

\subsection{Test carrier}

The test carriers are based on the two-cylinder parallel-twin Rotax 804 which is used in the motorcycle BMW F 800, but with a prototype crank train (Fig. 8). Table 2 shows the three different crank trains. The base compression ratio of all variants is 12 . The camshafts are optimised for $3000 \mathrm{rpm}$. To compare the extended expansion with a Miller engine, the base engine was adapted with a Miller camshaft and with a higher geometric compression ratio. As mentioned before, the Miller timing reduces the effective compression ratio. Inter alia, because of the quite slow valve closing, it is not possible to quantify neither the effective compression ratio nor the effective compression stroke exactly with Miller.

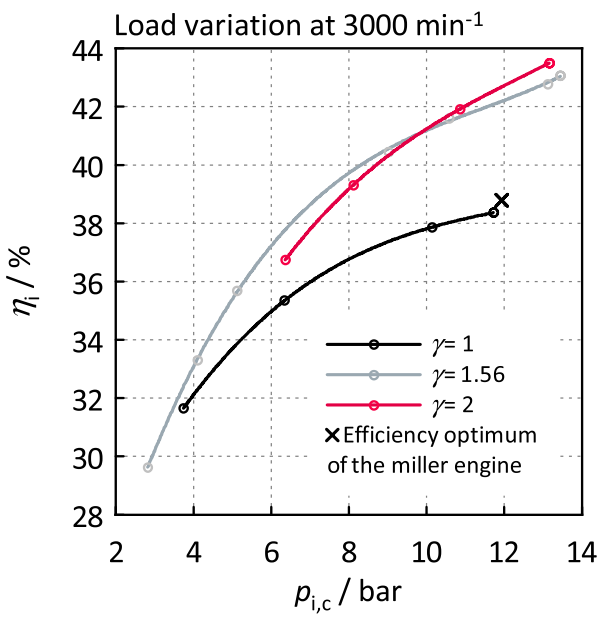

Fig. 9 Measured indicated efficiency for a throttle variation [9]

\section{Measurement results}

Numerous measurements have been conducted with the above mentioned test carriers. Speed, load, compression ratio, AFR and boost pressure were varied to investigate the characteristic of extended expansion.

Figure 9 shows the measured indicated thermal efficiency $\eta_{\mathrm{i}}$ versus mean effective pressure. The mean effective pressure $p_{\mathrm{i}, \mathrm{c}}$ is related to the (effective) intake volume. The load is varied by an intake throttle, the engine is operated stoichiometrically. The measured efficiency at full load of the engine with extended expansion with a volume ratio $\gamma$ of 1.56 is with $43.1 \%$ significantly higher than that of the conventional engine which reaches $38.5 \%$. At part load operation, the efficiency advantage of the extended expansion decreases. At part load operation, the gas exchange cycle becomes negative, because of throttling. The effect of a negative gas exchange cycle increases with higher volume ratio $\gamma$ [9]. Additionally, at the lowest loads, the pressure at the end of expansion is lower than the pressure in the exhaust system.

The efficiency advantage of the engine with the volume ratio of two is less, compared to the engine with $\gamma=1.56$. This is due to the badly shaped combustion chamber because of the short compression stroke. ${ }^{2}$ That causes a high wall heat flow, high unburned exhaust energy and a slow combustion.

The Miller engine has an unexpected low efficiency advantage compared to the conventional engine $(\times$ in Fig. 9 ). That is—again—due to a bad combustion chamber and a bad

\footnotetext{
2 What is not a general problem of extended expansion but a constructional property of this very engine.
} 
combustion as result of a reduced tumble [10]. Additionally, the inlet valve lift is restricted to about $4 \mathrm{~mm}$. Anyway, Miller timing - compared to the engine with extended expansion-has negative effects on principle, which will be discussed in detail in Sect. 5.2.

This paper focusses on the thermal efficiency of extended expansion engines. However, other parameters contribute to the feasibility of new engine concepts also. With this concept, the parameters friction, mass balancing and exhaust gas temperature may become critical. For further information, please refer to [11] (friction), [15] (mass balancing) and [9] (exhaust gas temperature).

\section{1D-CFD post processing}

With the measurements, it is possible to calibrate 1D-CFDsimulation models. These calibrated models were used to post-process the measurements, thus allowing to gain a deeper understanding of measured effects and to simulate variants, which were not measured before.

\subsection{Wall heat transfer}

The wall heat transfer plays a crucial role in the assessment of Atkinson-type engines. Prior to the measurements it was assumed that the unconventional piston movement has an impact to the wall heat transfer as the piston speed is one of the most important parameters. By simulative recalculation of the measured operating points it was possible to reveal the effects of the Atkinson piston movement to the heat transfer. This evaluation was supported by the direct measurement of the local instantaneous heat transfer using the surface temperature method [12]. It was shown that the concept of extended expansion has no major effect to the wall heat transfer compared to an conventional engine with the same compression stroke. The compression stroke and the piston movement around top dead centre have the strongest influence on the wall heat transfer. As there exist no significant differences in piston movement between an Atkinson engine and a conventional one during this phases of the process, there are also no significant differences in heat transfer. However, when using zero-dimensional heat transfer models the definition of the piston speed has to be considered. With models using the mean piston speed (Woschni, Hohenberg) best results were achieved, when the mean piston speed during expansion stroke was assumed as linearly rising over crank angle from top dead centre to the bottom dead centre. In [13] it is shown that the Bargende heat transfer equation, using the instantaneous piston speed, can cope with the Atkinson cycle piston movement without adjustment.
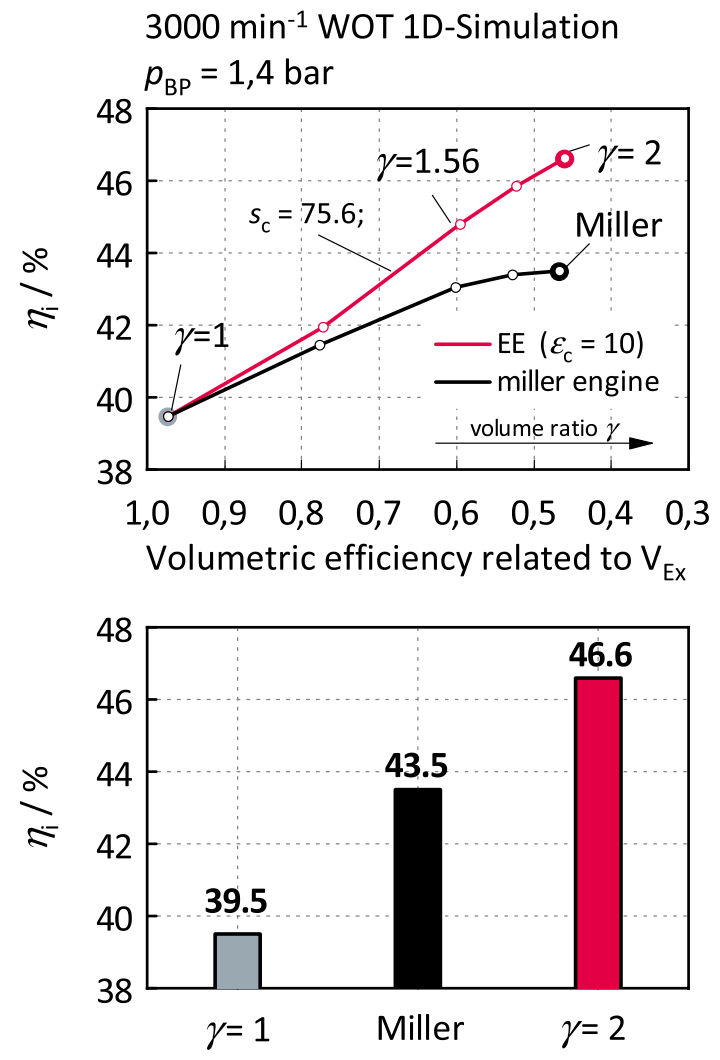

Fig. 10 Variation of the volume ratio and accordingly the volumetric efficiency

\subsection{Miller engine vs. engine with extended expansion}

As described in Sect. 4, the measured efficiency of the Miller cycle engine was disappointingly low. This was ascribed to a slow combustion and restricted valve lift. To identify further negative effects of Miller timing, simulations with the same rate of heat release were done. Following boundaries were used for these simulations:

- compression ratio $\varepsilon_{\mathrm{c}}=10$

- exhaust turbocharger, boost pressure $=1.4$ bar

- same rate of heat release for all points

Figure 10 shows the simulated indicated efficiency for the crank train solution and the Miller solution for different volume ratios. The volume ratio $\gamma$ is substituted by the volumetric efficiency, because with the Miller valve timing it is not possible to define an exact $\gamma$. Starting from the conventional engine (vol. eff. $=0.97 / \gamma=1$ ), the efficiency increases by increasing the volume ratio (decreasing volumetric efficiency). The variation of $\gamma$ is done by increasing the exhaust stroke for both variants that ensures 


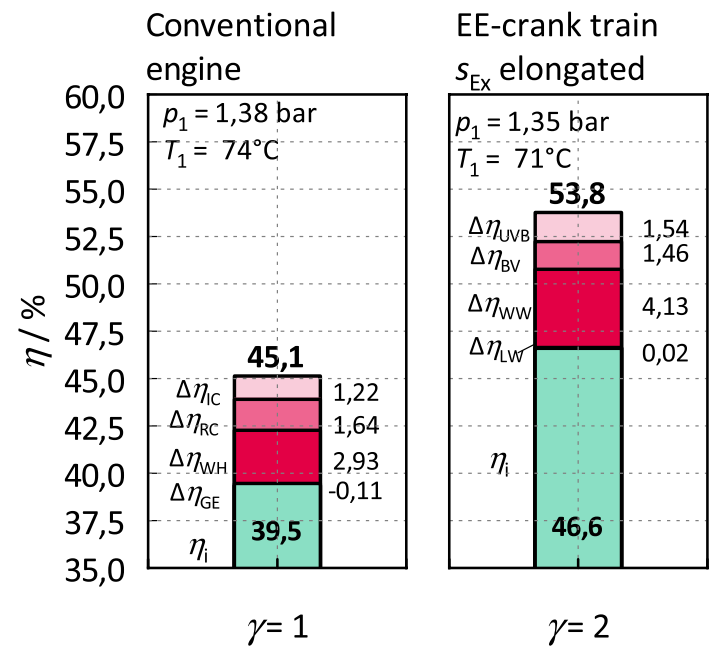

Fig. 11 Loss analysis; $n=3000 \mathrm{rpm}$ and WOT
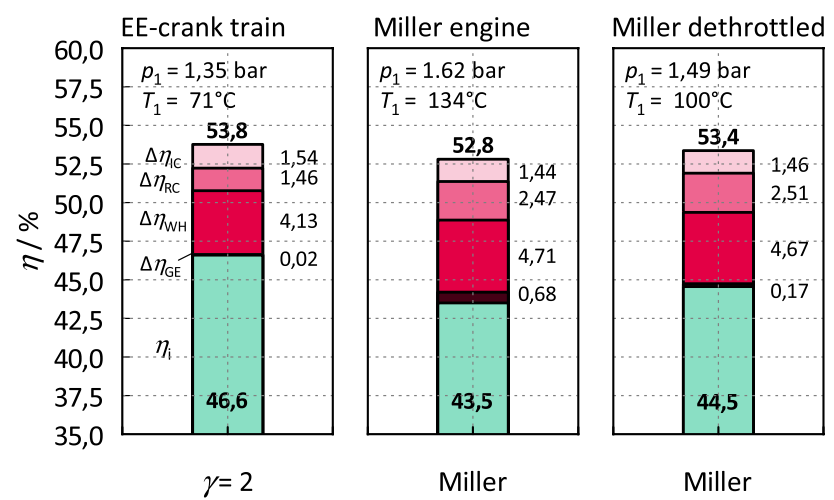

Fig. 12 Loss analysis; $n=3000 \mathrm{rpm}$ and WOT

identical geometrical boundary conditions for the standard air fuel cycle. The curves show a significant benefit for the crank train solution, what is additionally highlighted in the lower chart. A loss analysis reveals the cause for this clear difference. $^{3}$

Figure 11 shows the loss analysis of the conventional engine and the engine with extended expansion. Starting with the efficiency of the standard air fuel cycle with real cylinder charge, following losses are subtracted: loss from incomplete combustion $\Delta \eta_{\mathrm{IC}}$, from real combustion $\Delta \eta_{\mathrm{RC}}$, from heat transfer $\Delta \eta_{\mathrm{WH}}$ and the gas exchange losses $\Delta \eta_{\mathrm{GE}}$. The efficiency difference between the conventional engine and the engine with extended expansion is caused by the higher efficiency of the standard air fuel cycle of the latter.

\footnotetext{
${ }^{3}$ All loss analyses base upon post-processed measurements or simulated load cases.
}

The left two loss analyses in Fig. 12 compare the engine with extended expansion with the Miller engine. The efficiency of the Miller engine is three percent point lower than that of the engine with extended expansion. This is partly due to the higher gas exchange losses $\Delta \eta_{\mathrm{GE}}$. Likewise, the efficiency of the standard air fuel cycle is less. That is because of the higher start temperature $T_{1}$ of the Miller cycle. ${ }^{4}$ The higher temperature has two reasons. On the one hand, the (input) wall heat of the Miller cycle during the gas exchange is higher than for the conventional engine. On the other hand, the (output) work during aspiration of the Miller engine is lower than that of the engine with extended expansion, which also causes a higher gas temperature [9]. Furthermore, the loss from real combustion $\Delta \eta R C$ is higher, although the rates of heat release over crank angle are equal for both. That is due to the different kinematic of the crank train. The piston speed of the Miller engine near the top dead centre is higher than that of the engine with extended expansion. Thus, the combustion of the engine with extended expansion is closer to the isochoric combustion than that of the Miller engine.

The rightmost loss analysis in Fig. 12 shows a dethrottled Miller engine. That means an increase of the intake port area of $65 \%$ and an inlet valve that closes fast within $10{ }^{\circ} \mathrm{CA}$. These measures increase the efficiency of the Miller engine for one percent point. This is caused by the reduced gas exchange losses and the increased efficiency of the standard air fuel cycle. The latter is caused by the decreasing temperature at the start of the effective compression $T_{1}$. Thus, dethrottling acts in two respects on the efficiency, but it is not easy to realise.

These are simulation results that assume identical combustion. A realised Miller engine would have an even lower efficiency because the Miller timing reduces the combustion speed due to deteriorated charge motion [10]. In the case of the Miller engine, furthermore, the possible compression ratio may be reduced because of the higher knock probability due to the higher temperature $T_{1}$ at start of compression. That causes a lower realizable expansion ratio of the Miller engine compared to the engine with extended expansion.

\subsection{Supercharger versus exhaust turbocharger}

With conventional engines, exhaust gas turbocharging is generally better in terms of efficiency than mechanical supercharging. However, above considerations (see Sect. 2) indicate that on engines with extended expansion also supercharging can gain an efficiency benefit. Thus, these two charging concepts have to be compared again.

\footnotetext{
${ }_{4}$ Definition refer to Fig. 3.
} 

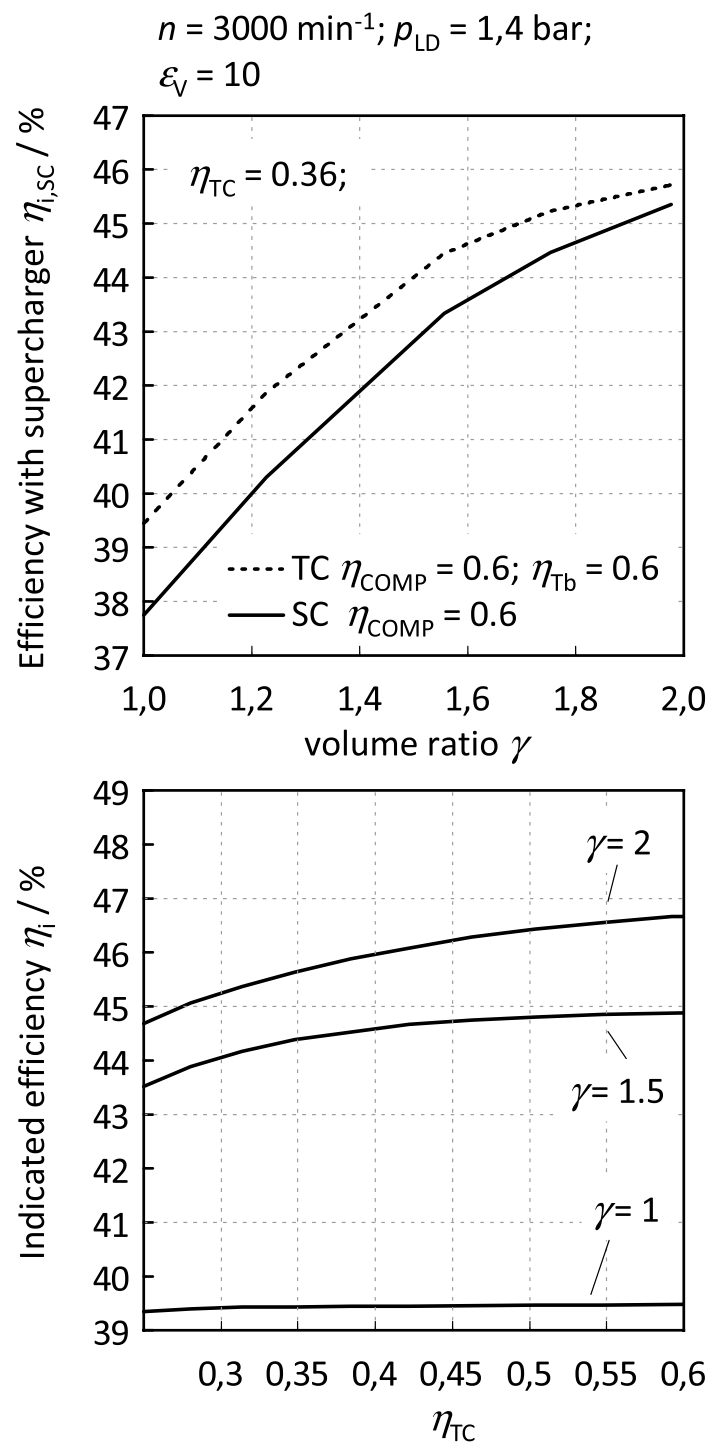

Fig. 13 Variation of the volume ratio for engines with exhaust turbocharge and supercharged engine

The upper chart of Fig. 13 compares the efficiency of the engine with exhaust turbocharger with the engine with supercharger as function of the volume ratio $\gamma$. With increasing volume ratio, the efficiency advantage of the engine to turbocharger decreases compared to the engine with supercharger. At high volume ratio, the required exhaust back pressure of the turbocharged engine increases because of the decreasing blow down energy. This causes high gas exchange losses of the turbocharged engine at high volume ratios. A supercharger with a (more) positive gas exchange loop could be the better solution.

The lower chart of Fig. 13 shows the influence of the exhaust turbocharger efficiency on the indicated efficiency for three different volume ratios. In the case of the conventional engine $(\gamma=1)$, the influence of the turbocharger efficiency $\eta_{\mathrm{TC}}$ is low. The blow down generates enough energy to drive the compressor. Below a certain turbocharger efficiency, the blow down does not supply enough energy and the back pressure has to be increased. In case of extended expansion, this threshold value is found at higher turbocharger efficiencies. Subsequently, the characteristics of the curves in the left chart depend on the efficiency of the turbocharger and the supercharger.

\section{Summary and outlook}

A broad-based survey tried to find a machine for passenger car propulsion with superior efficiency compared to conventional engines. Without any restrictions whatsoever thermal engines of various types were assessed. Unexpectedly, it was shown that a rather conventional process let expect the highest efficiency potential, and that is the reciprocation piston engine with extended expansion, i.e. an conventional engine with a modified crank train. The so-called Atkinson engine was investigated in detail by means of theoretical thermodynamics, measurements and engine process simulation.

The thermodynamic theory revealed some interesting differences to conventional combustion engines, mainly with respect to charging. It was shown that a mechanical supercharger can lead to increasing efficiency on extended expansion engines. Further, the theory identified an efficiency gain of almost 10 percent point for loss-free processes.

Three different test carriers with different expansion ratios $\gamma$ were used to confirm the predicted high efficiency potential of extended expansion. The test carriers used an stoichiometric Otto combustion process. It was found that the engine with a $\gamma$ of 1.56 had an efficiency 4.6 percentage points higher than the conventional engine at NA full load operation. It was also found that the extended expansion has no inherent effect on combustion, emission formation and wall heat transfer. However, due to restrictions of prototype construction this is most likely not the entire potential of extended expansion.

Based on these measurements, a thermodynamic 1D simulation model was built and calibrated. With this model it was possible to overcome the restrictions of the measurements, and it was found that a extended expansion engine with a $\gamma$ of 2 is most likely to gain an efficiency benefit of 7 percent point compared to a conventional engine with above boundary conditions.

However, for throttle controlled stoichiometric Otto engines, a serious deterioration of efficiency occurs at part load, with the extended expansion being very sensitive to pumping work. This favours such engines to be used in stationary or phlegmatized operation. 
Major effort was made to assess the Miller cycle as a thermodynamic alternative to the crank train solution. Measurements and simulations revealed that Miller suffers from inherent and also actual losses, cutting a substantial share of the efficiency potential of a equivalent cranktrain solution.

Considering mechanical issues such as friction [14] and mass balancing [15] it may nevertheless turn out to be more convenient to use Miller cycle process in short-term series solution [16] accepting some disadvantages in peak efficiency.

Acknowledgements Open access funding provided by Graz University of Technology.

Open Access This article is distributed under the terms of the Creative Commons Attribution 4.0 International License (http://creativeco mmons.org/licenses/by/4.0/), which permits unrestricted use, distribution, and reproduction in any medium, provided you give appropriate credit to the original author(s) and the source, provide a link to the Creative Commons license, and indicate if changes were made.

\section{References}

1. Meta Motoren- und Energie-Technik GmbH: Verfahren zum Umwandeln thermischer Energie in mechanische Arbeit sowie Brennkraftmaschine. Patentschrift DE 102006002925 B4, 25.02.2010 (2010)

2. Alten, H.: Thermodynamische Untersuchung eines 4-Taktmotors mit Nachexpansion. http://www.5-takt-motor.com/Dateien/TDReport\%20103\%20von\%20Hans\%20Alten.pdf (2012). Accessed 18 Sept 2012

3. Seneca, S.A.: Brennkraftmotor. Patentschrift WO 2008/101495 A2, 28.08.2008 (2008)

4. Ferrenberg, A.: Regenerated engine with an improved heating stroke. Patentschrift US 5632 255, 27.05 .1997 (1997)

5. Atkinson, J.: Gas engine. US Patent 364496 A (1887)

6. Bauer, M., Wurms, R., Budack, R., Wensing, M.: Potenziale von Ottomotoren mit einem zusätzlichen Expansionszylinder. 5. MTZ
Fachtagung. Der Ladungswechsel im Verbrennungsmotor, Stuttgart (2012)

7. Koga, H., Watanabe, S.: Research on extended expansion generalpurpose engine - heat release and friction. SAE Technical Paper 2007-32-0003 (2007)

8. Miller, R.: High expansion, spark ignited, gas burning, internal combustion engines. USA Patent 2773 490, 11 December 1956 (1956)

9. Dumböck, O.: Thermodynamische Untersuchungen von Ottomotoren mit verlängerter Expansion und anderen unkonventionellen Konzepten zur Wirkungsgradsteigerung. TU Graz, Dissertation (2016)

10. Scheidt, M., Brands, C., Kratzsch, M.: Kombinierte Miller-Atkinson-Strategie für Downsizing-Konzepte. MTZ 05(2014), 14-21 (2014)

11. Schutting, E., Dumböck, O., Eichlseder, H., Hübner, W., Schmidt, C.: Herausforderungen und Lösungsansätze bei der Diagnostik eines Ottomotors mit verlängerter Expansion. 11. Internationales Symposium für Verbrennungsdiagnostik, pp. 227-239 (2014)

12. Wimmer, A., Pivec, R., Sams, T.: Heat transfer to the combustion chamber and port walls of IC engines-measurement and prediction. SAE Technical Paper 2000-01-0568 (2000). https:// doi.org/10.4271/2000-01-0568

13. Langwiesner, M., Krueger, C., Donath, S., Bargende, M.: Wall heat transfer in a multi-link extended expansion SI-engine. SAE Technical Paper 2017-24-0016 (2017). https://doi. org/10.4271/2017-24-0016

14. Schutting, E., Dumböck, O., Kraxner, T., Eichlseder, H.: Thermodynamic consideration of the Miller cycle on the basis of simulation and measurements. In: Liebl, J., Beidl, C. (eds.) Proceedings of Internationaler Motorenkongress 2016. Springer, Wiesbaden (2016)

15. Pertl, P.: Engine development of an extended expansion engineexpansion to higher efficiency. TU Graz, Dissertation (2016)

16. Budack, R., Wurms, R., Mendel, G., Heiduk, T.: Der neue 2,0-1-R4-TFSI-Motor von Audi. MTZ 05, 16-25 (2016)

Publisher's Note Springer Nature remains neutral with regard to jurisdictional claims in published maps and institutional affiliations. 